\title{
Impact of Coronavirus Pandemic on Education
}

\author{
Edeh Michael Onyema $^{{ }^{*}} \quad$ Dr. Nwafor Chika Eucheria ${ }^{2} \quad$ Dr. Faith Ayobamidele Obafemi ${ }^{3}$ \\ Shuvro Sen ${ }^{4} \quad$ Fyneface Grace Atonye $^{5} \quad$ Dr. Aabha Sharma ${ }^{6} \quad$ Alhuseen Omar Alsayed $^{7}$ \\ 1. Lecturer, Dept. of Mathematics and Computer Science, Coal City University, Enugu, Nigeria \\ 2. Associate Professor, Dept. of Science Education, Ebonyi State University, Nigeria \\ 3. Lecturer, Faculty of Veterinary Medicine, University of Abuja, Nigeria \\ 4. Research Associate at BRAC University, Bangladesh \\ 5. Ph.D Scholar, Faculty of Education, Ebonyi State University, Nigeria \\ 6. Associate Professor, School of Education, GD Goenka University, Gurgaon, India \\ 7. Deanship of Scientific Research, King Abdulaziz University, Jeddah 21589, Saudi Arabia
}

\begin{abstract}
Coronavirus Disease (COVID-19) outbreak poses serious concerns to global education systems. Efforts to contain COVID-19 prompted unscheduled closure of schools in more than 100 countries worldwide. COVID-19 school closures left over one billion learners out of school. The study investigates the impact of COVID-19 on education. Data were collected through structured questionnaires administered to 200 respondents that consist of teachers, students, parents, and policy makers selected from different countries. The collected data were analyzed using STATA/Regression. The results show that COVID-19 has adverse effects on education including, learning disruptions, and decreased access to education and research facilities, Job losses and increased student debts. The findings also show that many educators and students relied on technology to ensure continued learning online during the Coronavirus pandemic. However, online education was hindered by poor infrastructures including, network, power, inaccessibility and unavailability issues and poor digital skills. The study underscores the damaging effects of COVID-19 on education sector and the need for all educational institutions, educators, and learners to adopt technology, and improve their digital skills in line with the emerging global trends and realities in education.
\end{abstract}

Keywords: Coronavirus, Education, School closure, Technology, Virtual learning, Covidiot.

DOI: $10.7176 / \mathrm{JEP} / 11-13-12$

Publication date:May $31^{\text {st }} 2020$

\section{Introduction}

The recent outbreak of the Coronavirus pandemic increased the gaps in the education sector globally. Though, the Coronavirus pandemic is novel, but it already has noxious effects on humanity. COVID-19 outbreak has created educational disruptions, and global health concerns that proved very difficult to manage by global health systems. As at now, no nation or race across the world is immune from the coronavirus pandemic, and the entire world seems overwhelmed by the speed of the spread and the devastating effects of COVID-19. The coronavirus pandemic has no boundaries, and the effect is large and fast. Just within few months of the outbreak of the disease, it has drastically changed the lifestyles of the entire world with billions of people being forced to 'stay at home', 'observe self isolations', and work and learn from home. It has limited the freedom of people to move, trade or associate. Not only has COVID-19 caused a total lockdowns in many countries across the world, but it also caused the death of thousands of people including, women, and the elderly. It was more worrisome to know that reports from various continents, including, America, Africa, Asia, and Europe indicated a daily increase in the number of new cases, and mortality due to COVID-19. As at April, 2020, the number of global COVID-19 cases has surpassed one million cases and more than 220 thousand deaths. It was also frightening that the USA recorded more than 2000 COVID-19 deaths in a single day despite the country's strong commitment to the fight against the contagion. The number of Coronavirus deaths was soaring with no immediate solutions in sight. The disease showed no sign of slowing down across the globe. The COVID-19 outbreak triggered the President of the United States, President Trump to invoke the "Defense Production Act". The government also issued a national emergency as a result of the growing number of new cases of Coronavirus in the country (Priscillia, 2020). The U.S government also negotiated with the parliament to approve more than 2 trillion US dollars stimulus package to combat the Coronavirus pandemic, and to provide some reliefs to citizens and businesses affected by the Coronavirus outbreak. Similar actions were also replicated in many other countries including, Germany where 810 billion US dollars were also set aside to contain the effects of the pandemic, yet the virus rapidly spread to many parts of the world.

The outbreak of COVID-19 affected all aspects of human activities globally ranging from education, research, sports, entertainment, transportation, worship, social gathering/interactions, economy, businesses, and politics. Indeed, the entire world was in distress as a result of COVID-19 threats, the reality of the situation was challenging to bear, and the education sector remains one of the worst-hit by Coronavirus outbreak. 


\section{Objectives of the Study}

The main objective of the study is to examine the impact of COVID-19 on education. Consequently, the study also investigated the various challenges that hinder continued/online education during the COVID-19 lockdown.

\section{Conceptual Framework}

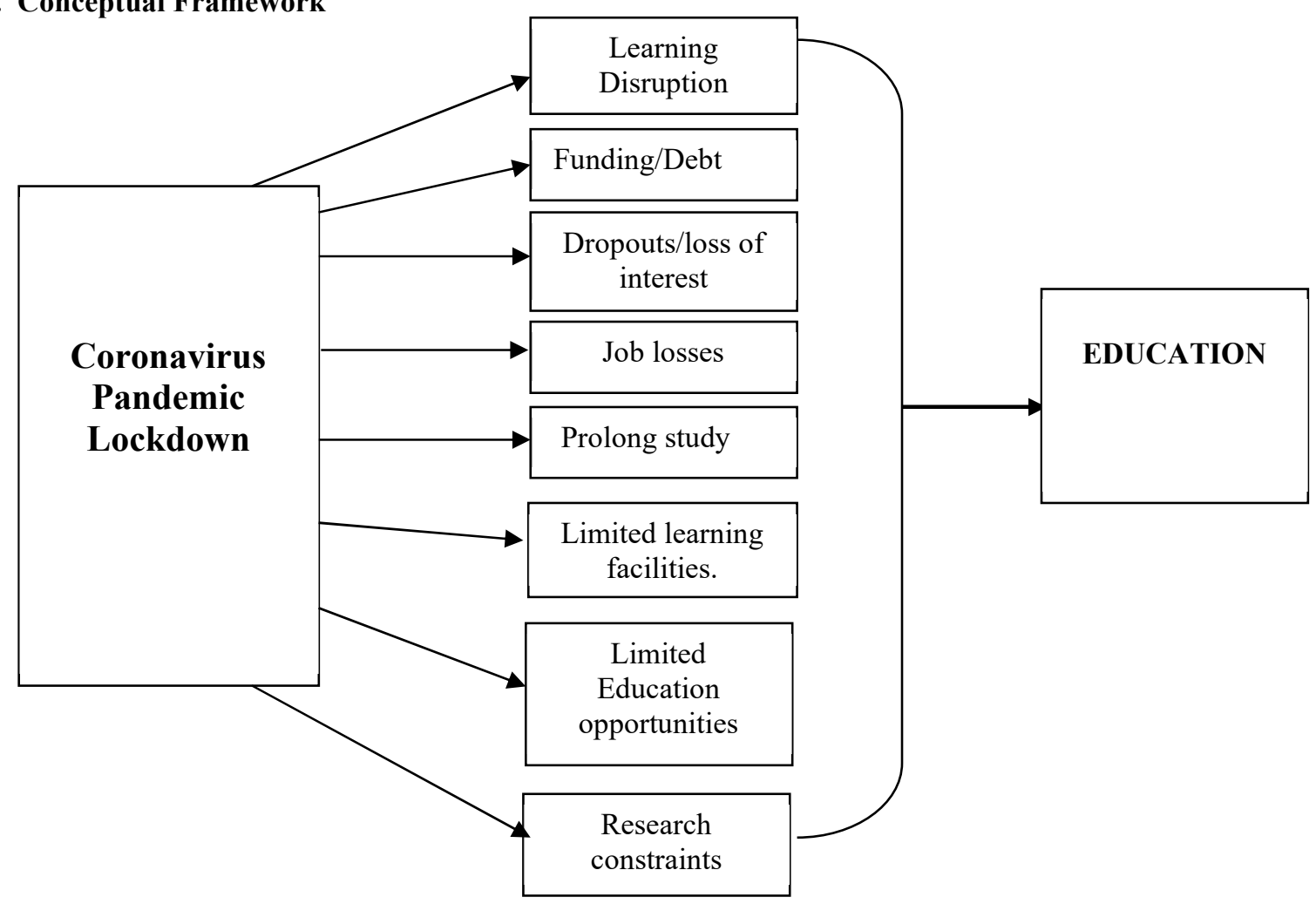

Figure 1: Conceptual Framework of the Study (Source: Researcher)

\subsection{Overview of Coronavirus Disease}

Coronavirus Disease is a contagious disease that first emerged in Wuhan, China in 2019. It was later coded "COVID-19" by the W.H.O which stands for Coronavirus Disease 2019. The Coronavirus outbreak remains one of the worst global pandemics for decades. The mortality rate soared and the easy of spread was upsetting. Research shows that older people and those with underlying medical problems like cardiovascular diseases, diabetes, chronic respiratory disease, and cancer were more likely to develop serious illnesses from coronavirus (W.H.O, 2020). Some of the symptoms of Coronavirus include; Sore throat, runny nose, constant coughing/sneezing, breathing difficulty and fatigue.

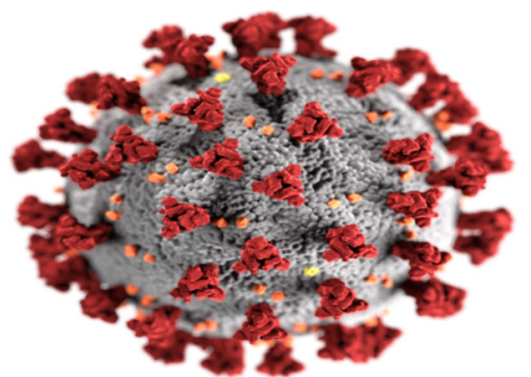

Image 1: Illustration of the Morphology of Coronaviruses; the club-shaped viral spike pelomers, coloured red, create the look of a corona surrounding the virion when observed with an electron (Wikipedia, 2020a-SARS-

$\mathrm{CoV}$-2 without background.png).

As at the time of this study, there were no reliable treatments for Coronavirus, but a series of researches were in the pipeline across the world towards finding a clinical vaccine for the contagion. However, recent events shows that behavioural change can help contain the spread of coronavirus. Some of the suggested measures to halt the coronavirus pandemic include;, improved individual habits such as personal hygiene, including constant washing of hands with alcohol-based sanitizers, good respiratory attitude (close coughing and sneezing), and other personal 
protection practices like wearing of face mask, social distancing, avoiding touching of the face, and reducing contacts with people through self-isolation at home or avoiding nonessential travels or gatherings. Coronavirus is a global problem that requires more action coordination and global cooperation to successfully contain the outbreak and to deal with its aftermath effects. Consequently, the United Nations appealed for 2 billion dollars to support global response efforts towards tackling the coronavirus pandemic. The consequences of COVID-19 could be more severe; if people do not comply or adhere strictly to public health regulations and advice.

\subsection{Global Responses to Coronavirus Pandemic}

A proactive response is critical to the containment of any disease outbreak, but the coronavirus took the world by surprise and most countries were not prepared initially for the pandemic, including the world powers. Shortly after the outbreak of COVID-19, the World Health Organization (W.H.O) issued guidelines and updates on how to mitigate the spread of the pandemic, and thereafter, many countries adopted different measures in addition to the W.H.O guidelines to contain the spread of the disease. There were lockdowns in most parts of the world, and people were asked to work from home. Some countries even deployed their military to enforce coronavirus restrictions, and to reduce the number of covidiots. There were increased demands for health equipment including, protective gowns, sanitizers, face masks and hand gloves. Countries like the United States and the U.K also opened their visitation doors for medical professionals such as doctors and nurses who were working or willing to treat the effects of COVID-19. Also, large gatherings and sporting activities were suspended at both local and international levels. Big sporting events like the prestigious European Champions League games were played behind closed doors before they were suspended. Global responses to Coronavirus pandemic were varied from country to country, but most countries endorsed the closure of school strategy as a means to contain the spread of COVID-19. Some selected COVID-19 responses across the world particularly as it relates to the closure of schools due to Coronavirus are highlighted below:

In the United States, many schools were closed down, and scheduled tests and examinations were also cancelled. The report shows that some of the schools closed down for Coronavirus in the U.S might not resume back for the rest of the academic year (Madeline, 2020). New York and the California States were among the worst-hit states in the U.S and the number of cases increased steadily despite strong measures put in place by both the federal and state governments to contain the pandemic. At a point, the country surpassed China in the number of cases of Coronavirus, but the country is determined to defeat the pandemic. School closures in the U.S affected over 60 million students in the country. In Spain, about 11 million students were affected by school closures for mitigation of the spread of Coronavirus. Regional governments in the country closed down schools in response to the increased cases of Coronavirus in the country. The closure of schools in Spain particularly in Madrid led to the suspension of job contracts for people who work at school cafeterias and in special education (El Pais, 2020). The closure of schools in Spain was very necessary considering that the country lost 849 people in a day due to Coronavirus. In Saudi Arabia, Middle East Monitor (2020), reported that schools and universities across the kingdom were ordered to close down for Coronavirus by the Ministry of Education. The government however, directed that "Virtual schools and distance education be activated to ensure that the educational process continues in an effective and quality manner".

In Australia, Michael (2020) reported that dozens of independent schools were shutdown at New South Wales while some moved to online classes. Students learn from home, while some schools were opened but implemented strong measures to ensure social distancing strategy. The opening of schools amidst the coronavirus pandemic was backed by the Australian government. The Prime Minister openly announced that schools remained open because the government believes that "children are at very low risk from coronavirus, and the closing of schools could have crippling effects on their health sector and the economy". The government cited solid health case for keeping schools open, but teachers and parents were worried (ABC News, 2020). The country also banned outdoor gathering of more than 2 people, while 18 billion dollars was also approved to mitigate the spread and effects of the Coronavirus. In Italy, schools were shutdown indefinitely, and the military were deployed to help enforce restrictions. However, despite the measures put in place by the government towards curbing the spread of Coronavirus, the country became an epicenter for the outbreak and recorded 969 coronavirus deaths in a single day.

In India, all schools and educational institutions were closed down and the government imposed "Janata" Curfew which restricted all citizens to stay at home to contain the spread of Coronavirus. The police also went round some cities to create public awareness about the pandemic.

In France, the government ordered the closure of all schools in a televised broadcast by President Macron. The measure was in response to the increased health crisis in the country due to coronavirus. The country was badly affected just like their counterparts in many parts of the world. The Coronavirus were reported to have originated from Wuhan, China and it was the epicenter at the beginning of the outbreak. Schools and other public institutions were shutdown to mitigate the spread of the virus. The closure of schools and other measures put in place by the government proved effective and the pandemic was contained to a large extent. The country also 
closed its borders with some neighbouring countries. In Iran, the government closed all schools as part of the preventive measures to halt the spread of coronavirus. Although, the country was among the epicenter of the coronavirus outbreak, and the death tolls in the country were high. The coronavirus increased Iran's economic problems, having been faced with economic sanctions from the West earlier. In Senegal, schools were shutdown to limit the spread of COVID-19. The country was the first sub-Saharan African country to close down schools due to coronavirus. In South Africa, the government directed all schools to close down in response to the coronavirus pandemic. This is in addition to the prohibition of social gatherings of more than 100 people. New cases were reported in the country and campaigns for behavioral changes were carried out to reduce the spread of the disease.

In Germany, schools were shutdown in response to the spread of coronavirus. The death rate due to coronavirus was reported to be low compared to their neighbours. The country also earmarked more than 800 billion dollars to fight the pandemic. In Russia, Schools were shutdown, and several other measures were taken to halt the pandemic. The death toll for coronavirus in Russia was reported to be low, but measures were put in place to contain the pandemic.

In Nigeria, the federal government ordered a total close down of all schools. The decision was largely applauded, and the National University Commission (NUC), a regulatory body for all universities in Nigeria also gave a follow-up directive to all universities in the country to shutdown. The government also suspended social gatherings, and workers were asked to work from home. An Italian who was reported to be the first case of coronavirus in Nigeria was successfully treated and discharged according to the government, but new cases emerged thereafter. Thus, the country needs to do more in terms of disaster preparedness and response. In Ghana, schools were shutdown to contain the spread of coronavirus disease. The government also released 100 million US dollars to enhance the fight against the pandemic. The country reacted proactively to contain the spread of the Virus. In Madagascar, the country has recorded zero COVID-19 death so far, and the country has claimed a breakthrough in Herbal medicine for COVID-19 treatment. However, the WHO issued warned that such claim has not been scientifically approved and cannot be recommended by the organization as cure for COVID- 19 .

It is important to note that while many countries were shutting down schools, some others like Singapore, Sweden, Brazil, and Australia kept their schools open as a kind of strategy to contain the contagion. The untimely closure of schools was good supportive measures to contain the spread of the disease, but it also had some adverse consequences on millions of students globally who were faced with multiple challenges in their education.

\subsection{Impact of Coronavirus Pandemic on Education}

The outbreak of Coronavirus negatively affected educational activities worldwide. The coronavirus pandemic affected educational systems worldwide, leading to the widespread closures of schools (Wikipedia, 2020b). It created serious disruptions in academic activities, as well as in career plans. As part of the global efforts to combat COVID-19, many countries across the world closed down schools in an attempt to contain the coronavirus pandemic. According to the United Nations Educational, Scientific and Cultural Organization (UNESCO) monitoring, over 100 countries implemented nationwide closures, impacting over half of the world's student population (UNESCO, 2020a). Even Britain, where Prime Minister Boris Johnson - one of those who earlier opposed the move, later admitted that "closing down schools could place further downward pressure on the upward curve of the Coronavirus outbreak"(ABC News, 2020). Some of the countries that closed down schools due to COVID-19 include, Nigeria, Ghana, Senegal, South Africa, China, Kazakhstan, Ethiopia, Honduras, India, Japan, Iran, USA, France, Spain, Italy, North and South Korea, Lebanon, Vietnam, Thailand, Germany, and South Korea just to mention but a few. School closures carry high social, educational and economic costs, and the disruptions they cause touch people across communities, but their impact is particularly severe for disadvantaged persons and their families (UNESCO, 2020b).

The disruption caused by COVID-19 in the educational sector may last longer than expected if a more reliable solution for coronavirus is not found on time, and the spread of the disease continues. UNESCO Director-General, Andrey Azoulayals cited by VOA News (2020), warned that "the global scale and speed of the educational disruption due to coronavirus is unparalleled and, if prolonged, could threaten the right to education". No doubts, unplanned school closures can cause severe problems for students, educators, parents and the society at large. It could negatively affect the academic interest and performance of students. If the students are not engaged productively, it could lead to idleness which might result in youth involvement in crimes, loss of interest in learning, and poor academic performance. The US Centre for Disease Prevention and Control (CDC) also expressed concerns about the implications of school closures. According to the CDC, "longer closures may result in more students congregating outside of schools. Quentin (2014), states that school closing is very controversial, and it can have spillover effects on a large number of students in receiving schools. It can affect the quality of teaching and learning and academic achievement particularly for students with special needs or those with learning difficulties that often requires more physical attention and guidance from the teachers. Though, technology can be used to remedy some of the fallouts from school closures, but it cannot replace the important effect of face-to-face 
interactions by students and teachers. Besides, many students do not have the necessary access to supportive technologies which makes it harder to maximize the potentials of learning technology during school closures. However, against all odds, mathematical model and empirical analysis of reactive closures of schools in past pandemics indicates that it reduces the total number of cases in the community by 25 percent and postpones the peak of the pandemic by a week or two, while proactive closures of school during pandemics remains one of the most beneficial interventions that can be employed to mitigate the impact of epidemic disease (Erika and Nicholas, 2020).

\subsection{Effects of Coronavirus School Closures}

School closure means the closing down of schools as a result of the pandemic, emergencies, labour strikes, disasters or deliberate efforts to reposition a school or curb crimes in a given campus or environment. This means that school closures are not only for emergencies or pandemics, but also a deliberate way of addressing some identified gaps in a given school. For instance, in Nigeria, the government or school authorities often shutdown schools to address security issues such as cultism, terrorism or violent protests on the campus. Gewertz (2009) cited in Ben, Mathew, and Kristen (2010) reported that "Obama's administration endorsed closure as part of an array of strategies to turn around 5,000 failing schools in the United States during his regime. Even though, school closures sometimes may be for good reasons, but the recent school closures for Coronavirus is detrimental to many educational systems across the world. As of 23 March, 2020, over 1.3 billion learners were out of school due to school closures in response to COVID-19 (Wikipedia, 2020b).

According to Erika and Nicholas (2020), school closures can either be reactive or proactive. Erika and Nicholas further stated that reactive closing schools occur upon the discovery of coronavirus case among the students, staff or parents. While proactive school closure occurs before the disease even reaches the doors of the school. Madeline (2020) opined that school closures due to coronavirus has posed new problems like how to make the transition to online and at-home learning, and how to cater for those who rely on school for food and housing security. School closures for coronavirus tends to increase pressures on students, teachers and parents especially those with limited digital skills, education and resources for continued education. It increases the burden on parents to not only struggle to provide for the home, but also to perform the supervision task of ensuring that their children learn from home. Unparalleled school closures increases the pressure on hospitals because they have to cater for as many health situations as possible that ordinarily could have been attended to by school health centers. Coronavirus school closures could increases student debt, extend the graduation time of students, and shatter the academic dreams of students, as well as programme schedules of educational institutions. Protracted school closures may result to increase rate of dropouts due to loss of interest and lack of resources to continue. If not well managed, school closures can also increase the rate of crimes, because prolonged school closures can lead to idleness which contributes to negative peer influences and youth involvement in crimes. Education jobs were also affected; many workers risks pay cuts or even disengagement from work during unscheduled school closures.

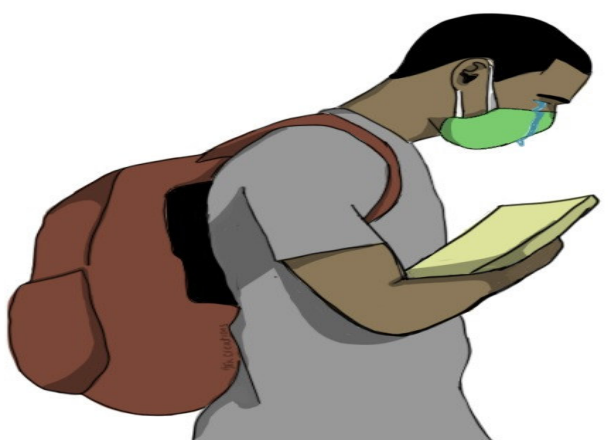

Image 2: COVID-19 Closure of school effects. (Source, Researcher)

According to UNESCO (2020b), some of the harmful effects of school closures for coronavirus are as follows: 1. Interrupted learning: School provides essential learning and when they are closed, students are deprived of opportunities for growth and development.

2. Nutrition: Many youngsters rely on free or discounted meals provided at schools for food and healthy nutrition. This is compromised as a result of school closures for coronavirus.

3.Unequal Access to digital learning portals: lack of access to technology or good internet connectivity for continued learning during school closures.

4. Increased pressure on schools and school system that remain open; Localized school closures place burdens on schools as parents tend redirect their children to open schools.

5. Social Isolation: Considering the fact that educational institutions are hubs for social activity and human interactions, school closures can deprive youth and children of some social communications and socializations that are essential to learning, development and creativity. 
Research activities were negatively affected because school closures and lockdowns limit researchers' ability to conduct researches particularly in situations whereby face-to-face interactions with students and teachers are required or access to school facilities or research laboratories were denied. School driven innovations and research are also affected during school closures.

Erika and Nicholas (2020) suggested that closing schools are not the only option to mitigate coronavirus. They advocated for authorities to give parents some flexibility to choose what is best for their families, while implementing stronger mitigation measures. However, in contrast to Erika and Nicholas's position, the president of the New South Wales Teachers Federation opposed the opening of schools during the outbreak of coronavirus. He believed that "the design of their schools and the size of the classrooms makes it impossible" to implement social distancing in schools (Michael, 2020). To mitigate the effects that accompanied the closures of schools, educators and learners had to rely on use of technological tools and platforms to ensure continued education. Consequently, it is important to admit in the present study that despite the perceived challenges imposed by school closures for coronavirus, the option remains one of the most effective measures to halt the spread of the pandemics.

\section{Technological Therapy for Coronavirus School Closures}

The unplanned closure of schools for COVID-19 came with obvious implications on the education industry globally even though; the decision to close schools appears to be right considering the need to contain the Coronavirus pandemic. The fortuitous closure of schools worldwide revalidated the need for adoption and deployment of cutting edge technologies in education. The outbreak of COVID-19 increased the global demand for online education. Technology has the potential to facilitate education from any location including home. Thus, as the world struggles to contain COVID-19 or any future outbreaks, the use of educational technology platforms would become the new reality for educational institutions, educators and learners. Technology is integral to student-teacher connection and communication especially in moments of isolations, quarantines, and lockdowns as a result of health crises and other emergencies. Technology is an essential tool to offer educational, psychological, spiritual, and medical advice or supports to parents, educators and students during and after pandemics. Technology aid report of cases, testing and social distancing which are critical to mitigate the spread of COVID-19. In some climes, robots and drones were also used to deliver goods to reduce human interactions. Staying at home all day could be very challenging for students especially the digital mmillenials who are very mobile and inquisitive in nature. Therefore, with the aid of technology, learners and educators can be productively and educationally engaged to reduce the boredoms that could push them become Covidiots during lockdowns for pandemics.

Educational institutions that have inculcated the use of emerging technologies in their systems before the outbreak of COVID-19 had a comparative advantage over those who were yet to embrace technology in their operations. Teachers were required to teach remotely and students needed adjustments to the new teaching and learning techniques. The transition to online education posed a challenge to learners in countries where there were no relevant infrastructures and facilities that facilitate online education. The problem of the digital divide was also a big issue particularly for learners in rural areas. This is because students and teachers in rural areas often lack the needed facilities and expertise to implement remote teaching and learning. While many lacks the required digital skills to implement online education. Technology remains a therapy to bridge the educational gaps that often emanates from unscheduled closure of schools during pandemics.

\section{Concept of Online Education}

Technology is a key component of education in the $21^{\text {st }}$ century. The increasing use of technology in education haa modified teachers' methods from the traditional approach that often place them as dispensers of knowledge to a more flexible approach where they act more as facilitators, mentors and motivators to inspire students to participate and learn (Onyema \& Deborah, 2019). Technology facilitates Remote learning, Distance learning,Virtual learning, Blended learning, Mobile learning, Distributed learning, Machine learning, Ubiquitous learning, Deep learning, Cooperative and Collaborative learning. Most aspect of education is going digital, and education stakeholders including students are confronted with the challenge of transition to online education. The use of appropriate educational technologies increases accessibility to learning resources such as Massive Open Online Courses (MOOCs), and multiple learning approaches to meet the need of diverse learners (Onyema et al., 2019).

Online education is a general concept for teaching and learning online with the aid of technology tools and platforms. The success of online education depend on factors including, good internet connections, learning software, digital skills, availability and access to technology. Online education platforms are vital tools that support inclusive education and online learning. Online education has its roots in distance education and the emergence of digital technologies that facilitate the efficient and reliable delivery of lectures, virtual classroom sessions and other instructional materials and activities via the internet (Onlineeducation.com, 2020). With the high penetration of the internet and mobile technologies across the globe, online education platforms can be maximized to bridge 
the gaps in education, thereby reducing the rate of global illiteracy. There are broad ranges of online education tools/platforms that facilitate online education particularly in times of outbreaks like the Coronavirus pandemic. Some of these technology tools/platforms are listed below:

1. GoToMeeting.com

2. Skype.com

3. Google Classroom/Open Online education (edu.google.com)

4. Youtube.com

5. Blackboard.com

6. udemy.com

7. coursera.org

8. memory.com

9. alison.com

10. edx.org

11. easyclass.com

12. vedamo.com

13. Khanacademy.org

14. TED-Ed (ed.ted.com)

15. Codeacademy.com

16. Stanford Online (Online.stanford.edu)

17. futurelearn.com

18. rcampus.com

19. learnopia.com

20. Peer 2 Peer University ( p2pu.org)

21. Teachers pay Teachers (teacherspayteachers.com)

22. Thinkific (thinkific.com)

23. MOOC.org

24. openculture.com

25. academicearth.org

26. itunesU Free courses (apps.apple.com)

27. lessonpaths.com

28. memrise.com

29. funbrain.com (for kids)

30. whyville.net (for teens)

31. Edmodo (edmodo.com)

32. schoology (schoology.com)

33. classdojo (classdojo.com)

34. google hangouts (hangouts.google.com)

35. Zoom (zoom.us)

36. Whatsapp.com

The use of educational technologies facilitates online education, student-teacher interactions, connection and relationships. It enhances teaching and learning experiences, content creation, course sharing, assessments, and feedback. Educators can reach and interact with their students on the go from any location, and lectures can be fixed at any time of convenience. Educators and students can optimize these technologies to supplement classroom teachings, and to improve their digital skills in line with emerging trends in education. More so, knowledge of technology increases educators' and students' interest, competence, confidence, creativity, employability and output, and also prepares them for the future.

\section{Challenges of Learning from Home}

The Coronavirus outbreak has forced millions of students to study and learn from home. This is not a new phenomenon because the home has long been epicenters of learning particularly as regards informal education. Learning from home is becoming a new normal for students. According to Education Task (2020), the majority of university students still prefer to study in the comfort of their own homes because the learners tend to have everything at their disposal without having to leave their chairs. However, the realities of receiving formal education from home could be very challenging to many educators, learners and parents especially those in developing countries where the accessibility, availability and use of technology in education are not widespread. Apart from the cost of accessing online education, many other factors such as network issues, poor power supply, distractions, poor digital skills, inaccessibility and availability issues can also hinder smooth study from home. There is also the problem of time to learn new technologies that might be required to learn from home, and noises that emanate internally or externally from neigbours and neigbourhood. Because unequal access to technology is 
another serious concern for many countries, prolonged school closures could deprive millions of students' access to education particularly those in third world countries, rural areas, and people with special needs. UNESCO understood these challenges, and efforts were made by them to help educators and students in the affected countries to teach and learn online from their homes through the provision of free software that facilitates remote education. Catherine (2020), reported that UNESCO assembled an online guide with links to distance learning apps and other resources to mitigate the effects of school closures for Coronavirus. Students were expected to optimize the Coronavirus mandatory school closures to improve their digital learning skills and home study habits. The challenges imposed by Coronavirus could be transformed into an opportunity by learners to advance their problemsolving skills and digital capabilities.

\section{Method}

The study adopted a survey design. Self-prepared questionnaires were administered to 200 respondents that comprised of educators, students, parents and policy makers selected from different countries, including Nigeria, Bangladesh, India and Saudi Arabia. Due to the lockdown, the questionnaires were administered online using online survey platform. Also, secondary data were also generated from newspapers, journals, media and reports during the review of literature. Thereafter, factorial analysis was carried out on the collected data using STATA.

\section{Results and Analysis}

8.1 Demographic Information of Respondents

Table 1: Distribution of respondents by Gender

$\begin{array}{lcc}\text { Gender } & \text { Frequency } & \text { Percentage } \\ \text { Male } & 120 & 60 \\ \text { Female } & 80 & 40 \\ \text { Total } & 200 & 100 \%\end{array}$

Table 1 above depicts the distribution of respondents by gender. It can be inferred from the table that $60 \%$ of the respondents were males while $40 \%$ were females. This implies that majority of the respondents were males.

Table 2: Distribution of respondents by educational qualifications

Educational Qualifications

Frequency

Percentage

$\begin{array}{lcc}\text { Undergraduate } & 110 & 55 \\ \text { Postgraduates } & 80 & 40 \\ \text { Others } & 10 & 5 \\ \text { Total } & 200 & 100 \%\end{array}$

Table 2 above shows the distribution of respondents by their educational qualifications. It can be inferred from the table that $55 \%$ of the respondents were undergraduates, $40 \%$ were postgraduates. While $5 \%$ of had other certifications. This implies that majority of the respondents were undergraduates.

Table 3: Distribution of respondents by Designations

Designations

Educators

Students

Others

Total

Frequency
80
110
10
200

Percentage

$100 \%$

Table 3 above shows the distribution of respondents by designations. It can be inferred from the table that $55 \%$ of the respondents were students, $40 \%$ were educators. While others were $5 \%$ This implies that majority of the respondents were students.

8.2 Regression analysis interpretation:

Table 4: Summary for the R value and R Square value with the Std. Error

\begin{tabular}{|l|r|r|r|r|}
\hline Model & \multicolumn{1}{|c|}{$\mathrm{R}$} & R Square & Adjusted R Square & Std. Error of the Estimate \\
\hline 1 & $.503^{\mathrm{a}}$ & .253 & .213 & .743 \\
\hline
\end{tabular}

a. Predictors: (Constant), Research constraints, Dropouts, Limited access to learning facilities, Learning Disruption, Prolong study, Job losses, Increase student debt, Limited education opportunities

b. Dependent Variable: Education

Table 4 provides the $R$ and $R^{2}$ values. The $R$ value represents the simple correlation and is 0.503 (the "R" Column), which indicates a high degree of correlation. The $R^{2}$ value (the "R Square" column) indicates how much of the total variation in the dependent variable, Education, can be explained by the independent variables i.e. 
Research constraints, Dropouts, Limited access to learning facilities, Learning Disruption, Prolong study, Job losses, increase student debts, Limited education opportunities, etc. In this case, $21.3 \%$ of the dependent variable can be explained by the independents variables.

Table 5: ANOVA result

\begin{tabular}{|l|r|r|r|r|r|}
\hline Model & Sum of Squares & df & Mean Square & F & Sig. \\
\hline 1 Regression & 28.213 & 8 & 3.527 & 6.386 & $.000^{\mathrm{a}}$ \\
Residual & 83.387 & 151 & .552 & \\
Total & 111.600 & 159 & & \\
\end{tabular}

a. Predictors: (Constant), Research constraints, Dropouts, Limited access to learning facilities, Learning Disruption, Prolong study, Job losses, increase student debt, Limited education opportunities

b. Dependent Variable: Education

From table 5, the Significance value is 0.000 (i.e. $p=.000$ ), which is below 0.05 and, therefore, there is a statistically significance of the technology for online education.

Table 6: Coefficient table with the $P$ value at $95 \%$ confidence interval

\begin{tabular}{|c|c|c|c|c|c|c|c|}
\hline \multirow[b]{2}{*}{ Model } & \multicolumn{2}{|c|}{$\begin{array}{l}\text { Unstandardized } \\
\text { Coefficients }\end{array}$} & \multirow{2}{*}{$\begin{array}{c}\text { Standardized } \\
\text { Coefficients } \\
\text { Beta }\end{array}$} & \multirow[b]{2}{*}{$\mathrm{t}$} & \multirow[b]{2}{*}{ Sig. } & \multicolumn{2}{|c|}{$\begin{array}{l}95.0 \% \text { Confidence } \\
\text { Interval for B }\end{array}$} \\
\hline & B & $\begin{array}{l}\text { Std. } \\
\text { Error }\end{array}$ & & & & $\begin{array}{l}\text { Lower } \\
\text { Bound }\end{array}$ & $\begin{array}{l}\text { Upper } \\
\text { Bound }\end{array}$ \\
\hline 1 (Constant) & 1.298 & .523 & & 2.481 & .014 & .264 & 2.332 \\
\hline Learning Disruption & .239 & .113 & .180 & 2.117 & .036 & .016 & .462 \\
\hline Student Debt & .080 & .095 & .076 & .841 & .402 & -.108 & .269 \\
\hline Dropouts & -.052 & .079 & -.052 & -.661 & .510 & -.209 & .104 \\
\hline Job losses & .236 & .097 & .223 & 2.443 & .016 & .045 & .427 \\
\hline Prolong study & -.104 & .094 & -.092 & -1.105 & .271 & -.291 & .082 \\
\hline Limited learning facility & -.071 & .093 & -.062 & -.765 & .446 & -.254 & .112 \\
\hline $\begin{array}{l}\text { Limited education } \\
\text { opportunities }\end{array}$ & .046 & .103 & .043 & .451 & .653 & -.157 & .249 \\
\hline Research constraints & .308 & .116 & .253 & 2.657 & .009 & .079 & .537 \\
\hline
\end{tabular}

a. Dependent Variable: Education

The first column shows the predictor variables (constant, Research constraints, Dropouts, Limited learning facility, Learning Disruption, Prolong study, Job losses, student debt, and Limited education opportunities). The first variable (constant) represents the constant, also referred to the educator efficiency as the Y intercept, the height of the regression line when it crosses the Y axis. In other words, this is the predicted value of COVID-19 impact on education, when all other variables are 0 . These coefficient table contains the values for the regression equation for predicting the dependent variable from the independent variable. These are also the values for $95 \%$ confidence intervals for the coefficients.

Table 7: Hypotheses testing comparing with the $P$ value

\begin{tabular}{|c|l|r|l|l|}
\hline $\begin{array}{l}\text { Hypothesis } \\
\text { Number }\end{array}$ & Variable Name & P Value & Statistically Significant & $\begin{array}{l}\text { Null Hypothesis } \\
\text { Accept/ reject }\end{array}$ \\
\hline H1 & Research constraints & .036 & Statistically significant & Reject \\
\hline H2 & Dropouts & .402 & Not statistically significant & Accept \\
\hline H3 & Limited learning facilities & .510 & Not statistically significant & Accept \\
\hline H4 & Learning Disruption & .016 & Not statistically significant & Accept \\
\hline H5 & Prolong study & .271 & Not statistically significant & Accept \\
\hline H6 & Job losses & .446 & Not statistically significant & Accept \\
\hline H7 & Student Debt & .653 & Not statistically significant & Accept \\
\hline H8 & Limited education opportunities & .009 & Statistically significant & Reject \\
\hline
\end{tabular}

From table 7, the null $\mathrm{H} 1$ and $\mathrm{H} 8$ are rejected. It indicates that due to COVID-19 research constraints and limited education opportunity variables are not accepted and therefore are not major effects. The other variables are accepted. It indicates that dropout rates, limited learning facilities, prolong study, job losses, student debt are significantly effects on education. 


\subsection{Factor Analysis}

From the factor analysis result on the students and educators, the eigenvalue of each factor was found. The following table contains the details:

Interpretation of the factor result:

$\begin{array}{lllc}\text { Factor analysis/correlation } & \text { Number of obs } & = & 200 \\ \text { Method: principal factors } & \text { Retained factors } & = & 4 \\ \text { Rotation: (unrotated) } & \text { Number of params } & = & 34\end{array}$

Table 8: Factor analysis result with Eigenvalue

\begin{tabular}{ccccc} 
Factor & Eigenvalue Difference & Proportion & Cumulative \\
\hline Factor1 & 5.05561 & 4.61660 & 0.9581 & 0.9581 \\
Factor2 & 0.43901 & 0.15952 & 0.0832 & 1.0413 \\
Factor3 & 0.27950 & 0.16776 & 0.0530 & 1.0942 \\
Factor4 & 0.11174 & 0.11911 & 0.0212 & 1.1154 \\
Factor5 & -0.00737 & 0.02599 & -0.0014 & 1.1140 \\
Factor6 & -0.03336 & 0.04418 & -0.0063 & 1.1077 \\
Factor7 & -0.07754 & 0.04984 & -0.0147 & 1.0930 \\
Factor8 & -0.12738 & 0.02710 & -0.0241 & 1.0688 \\
Factor9 & -0.15447 & 0.05437 & -0.0293 & 1.0396 \\
Factor10 & -0.20884 & --- & -0.0396 & 1.0000
\end{tabular}

From table 8 above, there were 10 factors found with their eigenvalue values. Initially, Factor 1 were recognized utilizing eigenvalue more than one (Cliff, 1988). This factor clarified 0.9581 or about $96 \%$ of the total variance. From the factor result with the Eigenvalue table, factor loading has been found Table 9: Factor loading value

Factor loadings (pattern matrix) and unique variances

\begin{tabular}{|c|c|c|c|c|c|}
\hline ariable & & & & r 4 & eness \\
\hline oor & 469 & 0.1802 & 0.1952 & -0.1327 & 933 \\
\hline choolpoli $\sim \mathrm{S}$ & 0.6707 & 0.3109 & -0.0248 & 0.0601 & 4492 \\
\hline liv $\sim e$ & 0.6893 & 0.3097 & -0.1525 & 0.0655 & 0.4013 \\
\hline Poorelectr $\sim \mathrm{y}$ & 0.7752 & -0.1377 & 184 & -0.1297 & 493 \\
\hline bi $\sim y$ & 0.7988 & -0.1001 & -0.1897 & -0.1195 & 3016 \\
\hline Networkiss $\sim$ s & 0.7142 & -0.2051 & -0.1857 & 0.1592 & .3880 \\
\hline Inade & 0.7428 & -0.2990 & 0.0337 & 0.0329 & 0.3566 \\
\hline$a \mathrm{a} \sim \mathrm{g}$ & 0.6527 & -0.0430 & 0.2590 & 0.1602 & 0.4794 \\
\hline $\mathrm{nd} \sim \mathrm{g}$ & 0.7083 & -0.1239 & 0.2546 & -0.0540 & 0.4152 \\
\hline esistance $\sim \mathrm{e}$ & 0.6953 & 0.1906 & -0.0043 & -0.0115 & 0.4800 \\
\hline
\end{tabular}

From the table 9 above, it can be seen that the factors were strongly associated with some particular factors. Innately, it shows the degree of which the factors loaded on the factors. A relatively high communality indicated that the variable had much in common with other variables. On the other hand, a relatively low communality means that the variable does not sustain an established relationship with other variables. The communality measurement is shown in table 10 .

Table 10: Measuring Communality from Uniqueness value

\begin{tabular}{|l|c|c|}
\hline \multicolumn{1}{|c|}{ Variables } & U = Uniqueness & $\begin{array}{c}\text { C = Communality } \\
\left.\sum \text { (loading }\right)^{2} \text { or (1- uniqueness) } \%\end{array}$ \\
\hline Poor digital skills & 0.4933 & $0.5067=51 \%$ \\
\hline School policies & 0.4492 & $0.5508=55 \%$ \\
\hline Digital divide & 0.4013 & $0.5987=60 \%$ \\
\hline Poor electricity & 0.3493 & $0.6507=65 \%$ \\
\hline Unavailability and accessibility & 0.3016 & $0.6984=70 \%$ \\
\hline Network issues & 0.3880 & $0.612=61 \%$ \\
\hline Inadequate facilities & 0.3566 & $0.6434=64 \%$ \\
\hline Lack of training & 0.4794 & $0.5206=52 \%$ \\
\hline Lack of funding & 0.4152 & $0.5848=58 \%$ \\
\hline Resistance to change & 0.4800 & $0.52=52 \%$ \\
\hline
\end{tabular}

The first identified components, has Eigenvalue more than 1.0, and the variables has factor loading of 0.5 or 
more have been chosen (Sen \& Antara, 2018; Sen, Antara, \& Sen, 2019). The main reason to choose these factors is that, factor loadings 0.5 and above are extremely noteworthy to determine the minimum loading necessary to comprise an item (Hair, Black, Babin, \& Anderson, 2006). An analysis of the factors loading identifies that the factors are significantly the most barriers to continued education during the COVID-19 pandemic lockdown. From the analysis, the finding confirmed that the ten factors are statistically significant as the communalities values for all of the variables are $<0.05$ and that explains the decision to the barriers of education during the COIVD-19 lockdown. All factors are influential. Among them, Unavailability and accessibility issues were the most affected. About $70 \%$ respondents agreed that Unavailability and accessibility issues hindered continued education amid COVID-19. Similarly, 51\% respondents agreed that poor digital skills hindered their engagement in continued educational activities during the COVID-19 pandemic lockdown.

\section{Discussion}

The study affirms the devastating effects of COVID-19 pandemic on education and the various barriers that hinder students and instructors engagements in online education for continued learning during the COVID-19 lockdown. The results show that educational activities were badly affected due to the COVID-19 pandemic lockdowns. Some of the identified effects include; learning disruption, limited access to learning facilities such as laboratories, job losses in the education sector, increase in students' debts, reduced funding for education, research constraints, and loss of learning interests among learners. The finding is in line with earlier assertion by Onyema et al., (2020), that Coronavirus pandemic created multiple problems for education sector leading to decreased education opportunities for underprivileged learners and those in rural areas.

Also, from the factor analysis, it was found that Poor digital skills, School policies, Digital divide, Poor electricity, Unavailability and accessibility, Network issues, Inadequate facilities, Lack of training, Lack of funding, Resistance to change, etc. are the major barriers for online education during the COVID-19 pandemic school closures. Among them, inadequate facilities appeared to be the highest impediment to online education during the pandemic. More than $70 \%$ of the respondents agreed that inadequate facilities such as lack of computer, internet facility, were the major factors that limited their engagement in Online education. Similarly, poor electricity service, unavailability and accessibility issues, network issues, etc. also created lots of problems for education during the COVID-19 lockdown. The result of the study shows that Coronavirus disrupted educational activities and tends to reduce educational opportunities for disadvantaged people. It displaced students and teachers and created multiple barriers in teaching and learning. The study indicates that COVID-19 lockdowns has the tendency to increase school debts and pressure on parents and educational institutions. This is in line with the assertion by Ben, Mathew, and Kristen (2010) that school closure can add stressors to students who are already contending with challenges associated with urban poverty. The finding recognizes the need for technology in education particularly in times of emergencies. This is in line with an earlier assertion by Onyema (2019), that integration of emerging technologies in education is no longer a choice, but a need for all educators considering the changing learning environment, demands for flexibility in methodology, and the need to enhance creativity and innovations in learning. The study would contribute to the growing knowledge on Coronavirus effect on education sector and the need for technology in education.

\section{Conclusion}

The study establishes that the Coronavirus pandemic has adverse effects on education. COVID-19 has major effects on school characteristics, including research, academic programmes, Staff professional development and jobs in the academic sector etc. These effects were felt by both educational institutions, educators, students and parents and other stakeholders in education. The study emphasizes the need for adoption of technology in education, as a way to curb the effects of Coronavirus and other future pandemics in education. Thus, the study acknowledges that the decision to shutdown schools for Coronavirus across the world may be hurtful, but it is sensible considering the rate of spread, and the dangers imposed by COVID-19 pandemic. The unprecedented school closures for Coronavirus remains a lesson and a warning to the entire educational world particularly those who are yet to embrace or adopt emerging learning technologies that support online or remote education. Stakeholders in the education sector have to develop robust strategies to deal with post-Coronavirus era.

\section{Future Work}

We are already working on a project to examine the implications of Coronavirus school closures on education of persons with disability particularly in developing countries. We also hope to investigate the effectiveness of virtual education during the COVID-19 lockdowns.

\section{Acknowledgement}

We acknowledge the educators and students of Coal City University, Nigeria; Southwestern University Nigeria; Ebonyi State University; GD Goenka University, India; and Pogil College of Heath Technology, Ijebu-Ode, Nigeria, for their participation in the survey and other contributions towards the success of the study. 


\section{References}

Advantages and disadvantages of studying at home | Education Task. (n.d.). Retrieved April 21, 2020, from https://www.educationtask.com/advantages-and-disadvantages-of-studying-at-home.html

Adverse consequences of school closures. (n.d.). Retrieved April 21, 2020, from UNESCO website: https://en.unesco.org/covid19/educationresponse/consequences

Alvarez, P. (2020, March 13). National emergency: Trump declares coronavirus emergency - CNNPolitics. CNN.Com. Retrieved from https://edition.cnn.com/2020/03/13/politics/states-coronavirus-fema/index.html

Barranco, J., \& Wisler, D. (1999). Validity and systematicity of newspaper data in event analysis. European Sociological Review, 15(3), 301-322. https://doi.org/10.1093/oxfordjournals.esr.a018265

Brummet, Q. (2014). The effect of school closings on student achievement. Journal of Public Economics, 119, 108-124. https://doi.org/10.1016/j.jpubeco.2014.06.010

Christakis, E., \& Christakis, N. A. (2020, March 16). Coronavirus: Closing the Schools Is Not the Only Option . The Atlantic. Retrieved from https://www.theatlantic.com/ideas/archive/2020/03/coronavirus-closingschools-not-only-option/608056/

Cliff, N. (1988). The Eigenvalues-Greater-Than-One Rule and the Reliability of Components. Psychological Bulletin, 103(2), 276-279. https://doi.org/10.1037/0033-2909.103.2.276

Coronavirus. (2020). Retrieved April 21, 2020, from World Health Organization website: https://www.who.int/health-topics/coronavirus\#tab=tab_1

COVID-19 Educational Disruption and Response. (2020, March 24). Retrieved April 21, 2020, from UNESCO.org website: https://en.unesco.org/news/covid-19-educational-disruption-and-response

Duffy, C., \& Ryan, B. (2020, March 19). Why are schools still open in Australia when coronavirus is prompting closures overseas? - ABC News (Australian Broadcasting Corporation). ABC News. Retrieved from https://www.abc.net.au/news/2020-03-19/coronavirus-why-is-australia-keeping-schools-open/12070702

File:SARS-CoV-2 without background. (2020). Retrieved April 21, 2020, from Wikipedia website: https://en.wikipedia.org/wiki/File:SARS-CoV-2_without_background.png

Hair, J. F., Black, W. C., Babin, B. J., \& Anderson, R. E. (2006). Multivariate Data Anal. (6th ed.). Analysis, 4-4.

Holcombe, M. (2020, March 18). Some schools closed for coronavirus in US are not going back for the rest of the academic year - CNN. CNN.Com. Retrieved from https:/edition.cnn.com/2020/03/18/us/coronavirusschools-not-going-back-year/index.html

Impact of the 2019-20 coronavirus pandemic on education. (2020, April 19). Retrieved April 21, 2020, from Wikipedia.org website: https://en.wikipedia.org/wiki/Impact_of_the_201920 coronavirus pandemic on education

Kirshner, B., Gaertner, M., \& Pozzoboni, K. (2010). Tracing Transitions: The Effect of High School Closure on Displaced Stud. Educational Evaluation and Policy Analysis, 32(3), 407-429. https://doi.org/10.3102/0162373710376823

McGowan, M. (2020, March 17). Coronavirus school closures: dozens of Australian private schools move to online learning | Australia news | The Guardian. The Guardian. Retrieved from https://www.theguardian.com/australia-news/2020/mar/17/coronavirus-school-closures-dozens-ofaustralian-private-schools-move-to-online-learning

Onyema, E.M. (2019). Integration of Emerging Technologies in Teaching and Learning Process in Nigeria : the challenges. Central Asian Journal of Mathematical Theory and Computer Sciences, 1(August), 1. 35-39.

Onyema, E.M., \& Deborah, E. C. (2019). Potentials of Mobile Technologies in Enhancing the Effectiveness of Inquiry-based learning. International Journal of Education (IJE), 2(1), 1-25. https://doi.org/10.5121/IJE.2019.1421

Onyema, E.M., Deborah, E. C., Alsayed, A. O., Noorulhasan, Q., \& Sanober, S. (2019). Online Discussion Forum as a Tool for Interactive Learning and Communication. International Journal of Recent Technology and Engineering, 8(4), 4852-4859. https://doi.org/10.35940/ijrte.d8062.118419

Onyema, E.M., et al. (2020). Pedagogical use of Mobile technologies during Coronavirus School Closures.

Sen, S., \& Antara, N. (2018). Influencing Factors to Stay Off-Campus Living by Students. International Multidisciplinary Research Journal, 8, 40-44. https://doi.org/10.25081/imrj.2018.v8.3698

Sen, S., Antara, N., \& Sen, S. (2019). Factors influencing consumers' to Take Ready-made Frozen Food. Current Psychology. https://doi.org/10.1007/s12144-019-00201-4

Saudi closes schools, universities because of coronavirus - Middle East Monitor. (2020, March 9). Middleeastmonitor. Retrieved from https:/www.middleeastmonitor.com/20200309-saudi-closes-schoolsuniversities-because-of-coronavirus/

Shu, C. (2020, March 17). UNESCO updates distance-learning guide for the 776.7 million children worldwide affected by school closures | TechCrunch. Retrieved April 20, 2020, from techcrunch.com website: https://techcrunch.com/2020/03/16/unesco-updates-distance-learning-guide-for-the-776-7-million-childrenworldwide-affected-by-school-closures/ 
Ten million students told to stay home in Spain in bid to slow spread of coronavirus. (2020, March 13). EL PAIS. Retrieved from https://english.elpais.com/society/2020-03-12/basque-country-galicia-and-murcia-closeschools-in-bid-to-slow-

coronavirus.html?fbclid=IwAR11_sqr1YCerswbmRvnO7UgKr9quMVvehQ9tgKdxkwtlidamgPitwIIBNM

The Evolution of Online Learning and Online Academic Programs. (n.d.). Retrieved April 21, 2020, from onlineeducation.com website: https://www.onlineeducation.com/

UNESCO: 290 Million Students Stay Home due to Coronavirus. (2020, March 7). Retrieved April 21, 2020, from learningenglish.voanews website: https://learningenglish.voanews.com/a/unesco-290-million-students-stayhome-due-to-coronavirus/5317148.html

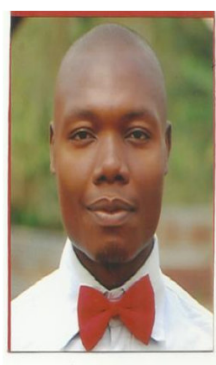

\section{ABOUT THE AUTHORS}

EDEH MICHAEL ONYEMA is a doctorate student at Ebonyi State University, Nigeria. He earned a Masters degree in Computer Science Education at Tai Solarin University of Education Nigeria. He has taught Computer Science courses to students at different higher institutions in Nigeria, including: Southwestern University Nigeria; Coal City University, Nigeria; Enugu State College of Education Technical (ESCET) Nigeria; and Pogil College of Health Technology, Nigeria. He has facilitated multiple professional development programmes for students and youths including members of the National Youth Service Corps (NYSC) Nigeria. Also, he has acted as "Guest Lecturer" for Online lecture series for various institutions including, GD Goenka University, India. His research interest includes Learning technologies, Mobile Computing, Machine learning, and IT Security.

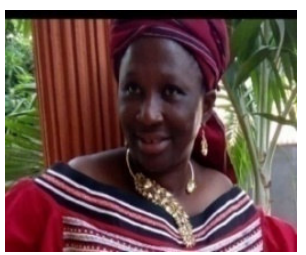

DR. NWAFOR CHIKA EUCHERIA is an Associate Professor at the Department of Science Education, Ebonyi State University, Nigeria. She is a seasoned educationist with several years of experiences in the Lecturing profession. She has published widely in high impact factor/indexed journals both at the local and international level. She has also mentored and supervised many students at different levels of education including Ph.D students.

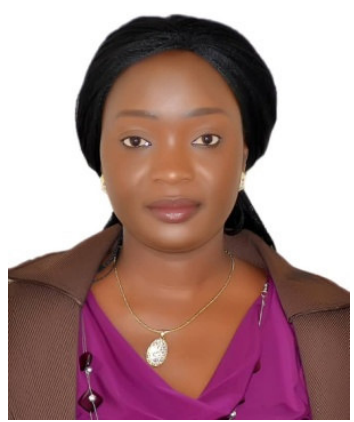

DR. FAITH AYOBAMIDELE OBAFEMI is a lecturer at the Faculty of Veterinary Medicine, University of Abuja, Nigeria. She is a Veterinary Doctor with a DVM (Doctor of Veterinary Medicine) degree from the University of Maiduguri, Nigeria, and a Masters degree (MSc Veterinary Physiology) from Ahmadu Bello University, ZariaNigeria. She has lectured at the Faculty of Veterinary Medicine of the prestigious University of Abuja since 2008. She has successfully taught and supervised the research works of many Veterinary doctors. She was also a Fulbright Research Fellow at the Department of Natural Sciences of the Bowie State University in Maryland, USA from August 2016 to May 2017 and discovered a potent anti cancer plant extract. She is currently working on her PhD. Her research interests include stress and ameliorating its effects on Physiology; cancer therapy and management; and infectious diseases that impact Physiology.

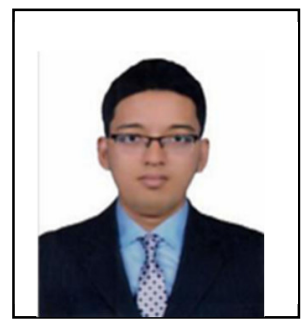

SHUVRO SEN is a Research Associate at BRAC University, Bangladesh. He also works as a Lead Researcher at "Friedrich-Ebert-Stiftung (FES), Bangladesh". He earned a master's degree in 'Strategic and International Management' and a Bachelor's degree in 'Management' from the University of Dhaka. His current research interest includes, Business and Management, Supply Chain Management (SCM), Technology and Education, Apparel Industry" etc. 


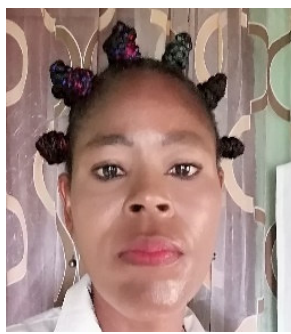

FYNEFACE GRACE ATONYE is currently a Ph.D student at Ebonyi State University, Nigeria. She earned a masters degree in Education Community Development at the University of Ibadan (2008). She has taught in different levels of education including, as an adjunct lecturer at Isaac Jasper Boro College of Education, Bayelsa State. She is presently a a School Supervisor (Nembe Zone) at the Bayelsa State Ministry of Education. She has also facilitated professional development programmes for Corps members as a Peer educator during the time of HIV awareness programme.

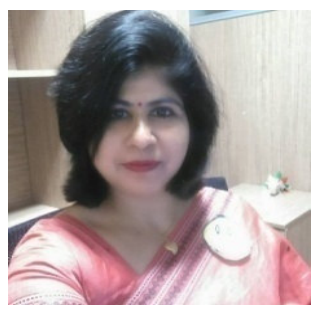

DR. AABHA SHARMA is an Associate Professor, and Head of Department at School of Education, GD Goenka University, Gurgaon, India. She has Ph.D. (Education); M.B.A (HR), M.Sc. (Chemistry), M.Ed., B.Sc. (Biology). She has taught in many educational institutions including, GD Goenka University; Glory Institute-Muscat; Christian Eminent College, Indore; Rajiv Gandhi College; IOE, D.A.V.V, Indore. She is a member of Global Educational Research Association, and All India Association of Educational Research. Also, she is a recipient of many merit awards including, Gold Medalist and First position holder in order of merit in the Uni. in M.Ed. She has published more than 30 papers and book chapters in both National and International journals/ conference proceedings.

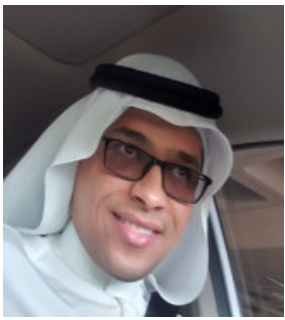

ALHUSEEN OMAR ALSAYED obtained a master's degree in Information Technology from University of Technology Sydney, Australia. He currently works as a Scientific Researcher with the Deanship of Scientific Research, King Abdulaziz University, Jeddah, Saudi Arabia. He is also a certified Trainer and professional practitioner from KAU and Technical and Vocational Training Corporation, Saudi Arabia. His research areas of interests include E-learning, cloud-based E-learning, collaborative learning, social networking sites, and other related topics. He has published many papers in indexed int. journals and conferences. He has been appointed as a Reviewer for IEOM GCC Conference. 